\title{
Cloud Computing: A Readiness Study among Small Financial Services Organisations ${ }^{1}$
}

\author{
Mick Gouweloos \\ Brian McArthur
}

\begin{abstract}
This article reports on the readiness for cloud computing in several financial services institutions from the Pietermaritzburg region. Cloud computing is viewed as being a disruptive technology, and there are real benefits for the adoption of this paradigm for service delivery. The study on which this article reports, investigated whether or not these small organisations are ready to take advantage of this technology. The researcher developed an initial framework for readiness, then interviewed three decision-makers - one from each organisation - and organised the data generated into a revised model for readiness. It has emerged that awareness and trust are key factors for these organisations. Counter-intuitively, cost saving has less of an influence than expected. There is limited literature in this specific context; this article therefore forms an initial basis for further research.
\end{abstract}

Keywords: Utility computing, data confidentiality, business readiness

\section{Introduction}

Perceptions of cloud computing include being as secure as the wispy tendrils of a real cumulus cloud. Financial services organisations, in particular, depend on confidentiality and security of data for their credibility and success. Can the computing cloud provide the necessary confidence in small financial services

${ }^{1}$ This article is drawn from an unpublished Honours research project. 
organisations that do not have information technology (IT) as a core competence, or will perceptions of possible evaporation deter adoption?

There has been much debate over the past few years on cloud computing as awareness of the topic has grown. The idea of cloud computing is not brand new; it is the realisation of a long-held dream of 'utility computing' (Armbrust et al. 2009). In the past, there have been Application Service Providers (ASP) and Software-as-a-Service (SaaS) providers, but there are several key differences when it comes to cloud computing (Goldner 2010). Cloud computing, simply described, can be broken down to be the sum of SaaS and utility computing. A 'cloud' refers to the hardware and software necessary to facilitate a data centre's function; this can be a public or private cloud (Armbrust et al. 2010). The service being sold when the cloud is public is called utility computing. SaaS is the delivery of applications over the Internet, which is similar to the service of ASPs.

As with any new technology, the issue of computing in the cloud, or cloud computing, is surrounded with confusion and more than a little misunderstanding. There are many differing conceptions of what computing in the cloud really is (Marston et al. 2010). Berkeley RAD Labs (Armbrust et al. 2009) define cloud computing as the software and hardware needed to deliver SaaS in the form of utility computing. Staten (2008: 3) defines cloud computing as "[a] pool of abstracted, highly scalable, and managed computer infrastructure capable of hosting end customer applications and billed by consumption'. Even so, there are several factors that are common in the cloudcomputing paradigm. These are scalability, elimination of large investment up front and on-demand use that eliminates the need for capacity provisioning (Armbrust et al. 2009; Lynn 2010).

Some examples of cloud computing services that are relevant to small businesses may assist in illustrating these definitions. Backup and storage applications such as Dropbox, productivity applications including Google docs and Google apps and communication services such as Skype are all examples of cloud computing services (Lynn 2010).

There are both positive opportunities and negative concerns for a business looking to take advantage of what cloud computing has to offer (Armbrust et al. 2010; Motahari-Nezhad et al. 2009; Yan 2010). The negative aspects of cloud computing revolve primarily around trust of how cloud computing is executed. Armbrust et al. (2010) examine some difficulties facing cloud computing as a paradigm, such as the guarantee of service availability. 
This is important because if a function is mission critical, then the service must be guaranteed. However, there are indications that cloud computing holds potential and is usable for small businesses (Staten 2008).

The seminal studies by Staten (2008) and Armbrust et al. (2009) on the topic of cloud computing were both conducted in the United States. No current academic literature is available in South Africa that is comparable; yet, there are some trade and conference articles on this topic. For example, the proceedings from the Cloud Computing Conference and Exhibition (2011) in Johannesburg reported the growing effect of cloud computing in South Africa. Thus, in the context of South Africa, there is limited academic research into cloud computing, in general. In particular, there exists a gap in the knowledge about cloud computing in the South African small financial services sector. The study on which this article is based made an initial exploration of the topic.

This study investigated readiness levels for cloud computing services among three small Pietermaritzburg financial service organisations. Cloud computing as a service is well suited to the smaller organisation (Staten 2008); yet, it is unclear whether there has been an adoption of this technology and whether the sector is aware of the possibilities of using this technology. The purpose of the study on which this article reports was to investigate the levels of readiness for cloud computing and why the levels are as they are. Semistructured interviews with key respondents were analysed qualitatively in extending and refining an initial conceptual framework, drawn from the literature. The sample was limited to financial services organisations because their core competencies are not IT-related yet they use IT for many services.

\section{Literature Review}

This study drew from practitioner literature as well as peer-reviewed journals due to the topical nature of the area of study. Cloud computing is a rising technology that is still 'getting underway in earnest' (Hayes 2008: 9).

There are both positive opportunities and negative concerns for a business looking to take advantage of what cloud computing has to offer (Armbrust et al. 2010; Motahari-Nezhad, Stephenson \& Singhal 2009; Yan 2010). These opportunities and concerns, drawn from the literature, are arranged here as a contextualisation of the position that a small business may find itself in when deciding upon whether or not to engage with the cloud computing model. 
The negative aspects of cloud computing revolve primarily around trust of how cloud computing is executed. Armbrust et al. (2010) examined some difficulties facing cloud computing as a paradigm, such as the guarantee of service availability. This is important because if a function is mission critical to a small business, then the service must be guaranteed. Linking to this is the bottlenecking of services, for example in a library system, as in the case of Yan (2010). Yan instituted cloud-computing services in a library and found that, occasionally, due to the nature of access to files in a library system, cloud computing created bottlenecks during file transfer. Having said this, however, increases in capabilities and infrastructure mean that this challenge will likely be overcome in future.

At the time of this research, there were several aspects that were debated within the context of cloud computing. The majority of debate, besides the concept of cloud computing itself, revolved around data confidentiality. Two schools of thought prevail within the literature. The first states that there is a high risk in allowing information to be stored at a location that is not under the control of the organisation (Iyer \& Henderson 2010; Kauffman, Ma \& Yu 2014; Morgan \& Conboy 2013; Vignos, Kim \& Metzer 2013). The implication is that the host that controls the cloud would be able to access the information and could misuse it (Iyer \& Henderson 2010). Kaufman (2009) claims that cloud computing depends on trust between vendors and customers. Jackson (2010) reports on Stroud's assertion that many information technology (IT) managers are concerned with keeping their data safe. This was a comment on a survey of 1800 IT managers in the United States performed by the Information Systems Audit and Control Association (ISACA) in 2009 (Setyono 2010). Opposing this view, are those who hold that cloud-computing vendors will have security as a core competency (Vignos, Kim \& Metzer 2013). This would make using the cloud vendor even safer than in-house security, which is often seen as a necessary evil (Staten 2008). Some authors (for example, Yan (2010)) suggest a middle road, that the organisation should encrypt their information before uploading it to the cloud. This seems like a sensible suggestion yet the literature does not reveal much more on the success of this strategy.

Moving from challenges to opportunities, there are several key aspects of cloud computing that make it ideal for small to medium businesses (Motahari-Nezhad et al. 2009). There are three main benefits that can be obtained through cloud computing. Firstly, scalability is especially useful for smaller businesses that may be expanding. Under normal circumstances, they 
would either need to provide for the expansion in their IT planning or continually upgrade as they go. This represents a strong cost saving over time that has real business implications (Goldner 2010; Misra \& Mondal 2010).

On a related point, there is no longer the need for a large initial investment that is often prohibitive for smaller businesses in developing solid IT systems (Armbrust et al. 2010). Carr (2003) posits that IT is becoming commoditised and should be used like a utility. Following this, Rappa (2004) asserts that cloud computing has the characteristics of a utility and the major business benefit in this is that the service is on-demand, the implication being that cloud consumers will pay the same for one server for a thousand hours as they would a thousand servers for one hour (Joshi \& Ram 1999). This links with scalability as well to provide compelling reasons for using cloud computing.

As an aside, the research by Staten et al. (2008) into the cloud computing market for large enterprises has shown that there are currently significant barriers for large enterprises to using cloud computing. This research found that large enterprises had concerns about stability, security and the lack of independent software vendor support. These findings may have some implications for small businesses yet the research maintains that cloud computing would be useful for small businesses (Aljabre 2012; Staten et al. 2008).

The following research questions informed the study:

- What are current readiness levels in Pietermaritzburg financial service organisations for cloud computing services? Cloud computing services are relatively new, and it is possible that financial service organisations are not yet aware of the technology or they are not in a position to adopt this technology despite its potential for savings. Thus, the current research had to ascertain whether participating businesses were ready for this new technology.

- Why are the readiness levels where they are? There are many factors generally affecting the rate of adoption of a technology. There are also reasons specific to a sector, industry or country. The current research aimed to let the combination of factors that represent readiness emerge from the data in an exploratory manner; following which the researcher 
attempted to analyse why readiness levels are as they are in this specific context.

- How would cloud computing affect IT within Pietermaritzburg financial service organisations? Nicholas Carr, in his article 'IT Doesn't Matter' (2003) discusses the commoditisation of IT and the services rendered by IT. Taking this view into account, it is possible to say that if a business's core competency is not IT, yet they must maintain computer services to operate, then they could certainly benefit from a service like cloud computing. Therefore it would be pertinent, in this context, to extrapolate how adoption of cloud computing would affect the IT of these financial institutions (Carr 2003). Moreover, this research question allowed the study to explore whether there were other factors affecting readiness, possibly missed above due to a lack of awareness of cloud computing.

\section{Conceptual Framework}

For the purposes of this study, there was relatively limited theory available about the factors that affect readiness for cloud computing. Therefore, a conceptual framework was derived from the literature, as a summation of the considerations in the decision of whether or not to adopt a cloud computing IT infrastructure. Two constructs have been created in order to analyse readiness levels: readiness for technology and business readiness. These are subdivided as follows.

Technology readiness:

- Stability

- Market support

- Market behaviour

- Security

Business readiness:

- Operations

- Infrastructure

- Cost saving 


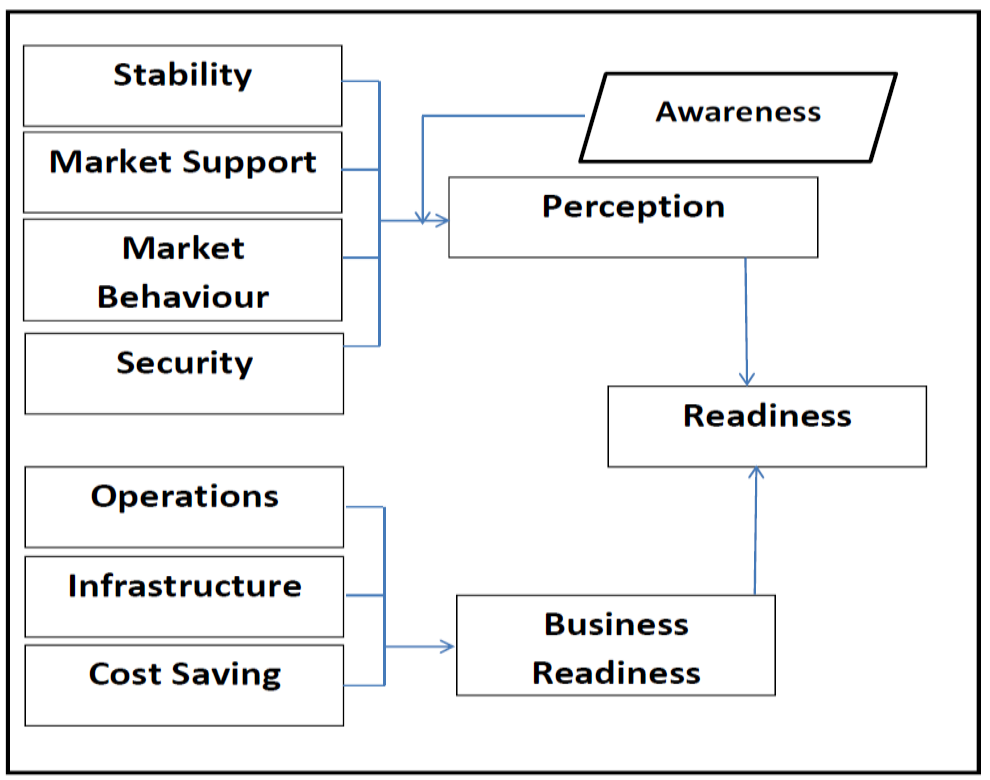

Figure 1: A conceptual framework for the analysis of an organisation's readiness for cloud computing

Perception as a construct is an important contributing factor to whether or not an organisation is ready to accept the cloud computing paradigm and use cloud services (Kauffman, Ma \& Yu 2014; Morgan \& Conboy 2013). If an organisation has a negative perception of technology then they are unlikely to accept the technology and be ready to use it.

\section{Technological Readiness}

Stability is very important for a company that uses IT for any number of its operations (Iyer \& Henderson 2012). If an organisation is going to adopt cloud computing as a service then the perception must be that the service will be stable enough to support its operations without server failures affecting operations, loss of data or loss of performance (Morgan \& Conboy 2013).

Many commercial cloud services are currently not supported by independent software vendors (Staten et al. 2008), which may make potential 
cloud users hesitant. Until there is a wider adoption within the information systems industry, this will be an inhibiting factor.

Staten et al. (2008) discuss references from larger organisations as a factor for readiness and claim that many organisations will not divulge whether or not they are using cloud computing. At the same time, they argue that many organisations will use cloud computing in a prototypical manner (Staten et al. 2008). This builds upon what they mention earlier, namely that, until the market shows signs of seriously undertaking cloud computing, many companies will be hesitant to adopt the paradigm.

As mentioned above, security is a contentious issue where cloud computing is concerned (Kauffman, Ma \& Yu 2014; Morgan \& Conboy 2013). However, regardless of individual situations, a business may not be ready to adopt cloud computing as long as they believe that the system is not secure (or can be made secure with minimal effort).

Awareness is a moderating variable because the organisation must be aware of the technology in order to be ready for it.

\section{Business Readiness}

Apart from the perceptions of cloud computing, there are real business implications for cloud computing. Business readiness as a construct therefore looks at whether it makes business sense to use cloud services.

The core competencies of an organisation have implications for which cloud computing services would be used (Iyer \& Henderson 2010). At the same time, some services lend themselves to the cloud-computing paradigm. This would influence the organisation's decision of whether it is ready for cloud computing.

Although not mentioned in the literature explicitly, the current research explored the possibility that the existing infrastructure may play a part in readiness for cloud services (Iyer \& Henderson 2010; Kauffman, Ma \& Yu 2014; Morgan \& Conboy 2013). This is due to a sunk-cost principle: if the business has invested heavily in IT infrastructure then they may be hesitant to move their operations to the cloud (Marston et al. 2011).

In general, businesses exist to make a profit. Thus, the cost savings of moving to the cloud is a serious factor in readiness. More important, however, is are the awareness of these savings and the calculation of a return on investment when considering cloud computing services. Misra and Mondal 
(2010) provide a sample analysis of this cost saving, as is discussed in the subsection below.

\section{Analysing Technology Readiness}

As with any emergent technology, there is a large amount of hype surrounding cloud computing. In assessing whether or not a company is ready for the adoption of a technology, Gartner's hype cycle (Linden \& Fenn 2003; O'Leary 2008) shows how different technologies may perform. At the same time, the model looks at the profile of organisations that adopt technologies at different times on the hype cycle. Thus, a company may be open to innovation and attempt to gain early-adoption advantage, while being aware that there are risks involved with this approach (Linden \& Fenn 2003). The type of firm will also have an effect on their readiness for a technology.

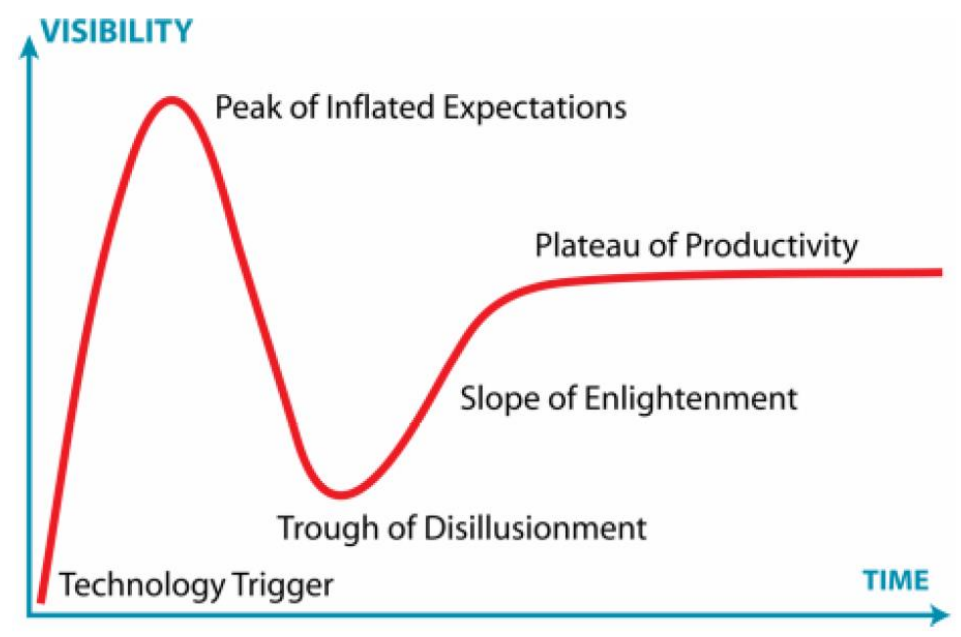

Figure 2 - Gartner's Hype Cycle Model (Linden \& Fenn 2003).

\section{Literature Review}

This qualitative, exploratory study followed an Interpretivist paradigm. The target population comprised all small financial services organisations in Pietermaritzburg. 
The sampling used in this study was purposive and, as such, three financial services institutions within the Pietermaritzburg region were targeted for interviews. These were conducted at the institutions' choice of venue and time. At these three companies, senior managers or the owners were interviewed to assess the company's readiness for cloud computing. The interviews were recorded and transcribed within a week of the interview.

Senior staff members generated data by using semi-structured interviews. The type of data from this study was relatively unstructured so a conversational interview was used. As the study was primarily exploratory, aspects of the grounded theory philosophy (Glaser 2001) were used in the generation and analysis of the data. The grounded theory process was not rigorously implemented; yet, the mind-set of allowing the theory to emerge from the data was employed. Having said this, Staten et al. (2008) conducted large-scale research into cloud computing in the United States of America (USA) using interviews. One of the difficulties they had was obtaining interview responses from large organisations, as they were hesitant to advertise the fact that they used cloud-computing services.

Over the course of the interview process in this research, the instrument evolved as new avenues of information revealed themselves. There were some considerations, both in the industry of financial services and in this context, that were not covered in the theory, and the instrument evolved to incorporate this. This allowed the research to cover a more relevant range of data from the respondents as well as follow the conversational manner of interviewing. This also fitted in with the grounded theory philosophy adopted in the analysis phase by allowing the respondents to express the factors that were important to them. In this study, organisations that were approached to participate were also reluctant. The three that agreed to participate did so on condition of strict confidentiality.

In conducting the research for this study, the researcher followed the guidelines of ethical research. In particular, all personal and organisational data will remain confidential. As indicated, this was an express requirement from participating organisations.

\section{Data Analysis}

The approach taken in this research has been to propose a conceptual model for the readiness for cloud computing in Pietermaritzburg and then to gather 


\section{Mick Gouweloos \& Brian McArthur}

qualitative data to see whether or not the data fitted in with the proposed conceptual model from the literature. This was an explorative study in a new context so the result was that the issues arising appeared quite different from the literature. The researcher compared the results of the interviews to the conceptual model in order to gauge how realistic the model was in representing whether or not organisations in Pietermaritzburg were ready for cloud computing. Furthermore, the data was viewed from a grounded theory perspective in order to let a new model emerge from the data. This was contrasted and compared to the proposed conceptual framework in a 'beforeand-after' manner.

Thematic analysis was conducted in order to extract specific themes that emerged from the unstructured information that was obtained. The framework for the analysis was based on the work of Sandelowski (1995). Sandelowski differentiates between data analysis and interpretation. She views two processes: looking at the data to find out what to look for in the data. Some points taken from this framework for analysis were: getting a feeling for the whole dataset, identifying key topics and extracting evidence for the themes (Sandelowski 1995).

The process that was employed in this study consisted of reading through the transcribed interviews in order to get a 'feel for the data'. The data generated from the interviews was then converted from raw data into the key points or issues that arose throughout the interviews. This was in line with the process of identifying key themes or topics. Lastly, the themes were extracted and formalised into a new model that was compared and contrasted to the original model. Of these issues, some aligned with the initial conceptual framework and some were new factors previously not indicated in the literature. Thus, a new conceptual model was created by incorporating the factors indicated by the respondents into the original model.

\section{Findings}

Within the pool of the respondents, there were two similar cases that provided a basis for identifying the factors affecting readiness as well as a dissimilar case where the use of a cloud-computing paradigm was mandated through a franchise or networked model of distribution. The last case was valuable because it provided a different view on the factors influencing readiness. These three cases formed the body of data gathered, and the issues were identified as 
common or specific to individual organisations. The factors are each explained and their relative importance (as gathered from the interview) will be indicated. The factors that emerged were all mentioned in the interviews and the importance was gathered from how they were stated in the interview. For example, one respondent said, 'Security of information is a very big thing for us', which indicated the importance of this factor to the respondent. The following factors emerged from the data as important contributors as to whether a company is ready for the cloud-computing paradigm. These factors are listed in an order that will be used to show the evolution from the original proposed model to the revised model.

Two key factors to emerge were trust and risk. These two terms are used together because many of the risks or concerns highlighted arose from a lack of trust of the cloud computing paradigm as well as the Internet in general. Trust also seemed linked to knowledge of or experience with technology; yet, this was not explicit from the data. Trust seemed to be a contributing or underlying factor for many smaller issues that arose during the interviews such as willingness to learn the new paradigm, willingness to cross over to a new paradigm as well as perception of the service provided by cloud computing.

Some comments made during the interview process were for instance, 'we need to be sure first', in the context of whether or not the organisation would be willing to use the cloud for storage. Another comment was, 'people just don't trust the service yet ... [p] eople wouldn't want to lose control of their data'. Conversely, in the case of a positive respondent, the following comment was made, 'it may require more education in order to use the service ... but that is not a problem'. These comments taken together underscore the fact that trust has a role to play in willingness to learn and cross over to the cloudcomputing paradigm.

Awareness was a primary factor in the data. All three respondents had little or no awareness of cloud computing. Two of the respondents had a vague idea of the concept of cloud computing but it was superficial at best. Illustratively, one respondent echoed the Star Wars character Master Yoda's language construction, 'the terminology of cloud computing I am not aware of' and another said, 'I have just heard about the terminology'. Awareness was a moderating variable within the original framework, and will most likely remain one. Having said this, it was clear throughout the interview process that the lack of awareness severely limited the respondents' ability to see the benefits and/or risks of cloud computing. In one case, the company was actually using 


\section{Mick Gouweloos \& Brian McArthur}

a cloud service within their organisation for a large part of their everyday running operations, yet the interviewee was completely unaware of the fact that they were using cloud computing.

The next factor that emerged from the data was an amalgamated one from several similar factors, named Performance. This is a category that encompasses issues such as safety, reliability, efficiency, competency and accessibility:

- Safety: a key issue for all the respondents was how safe their data would be if they use cloud computing;

- Reliability: users want to be able to use the service at any time incorporating downtime for the service. There were several concerns for respondents including, 'if we cannot access our information then our business would be crippled';

- Efficiency: users expected to have the service provide at least the same efficiency of use as current IT. Illustratively, one response said plainly, 'guarantee of service is very important';

- Competency: also mentioned as a support issue in that users need to have access to help when necessary, and

- Accessibility: The users need to access the data they need when they need it.

Another factor that emerged as important in the companies' readiness for cloud computing was how the new service would fit in with existing IT. This is especially relevant when organisations have a suite of programs that interact to provide a holistic service. This is also important when considering whether the service would interface with other companies' IT. An example could be Customer Relationship Marketing (CRM) software that the bank would distribute to financial planners. The cloud service must be able to interface with that format in order to meet the organisation's needs. Also important here is whether or not there is a cloud service currently available in the vicinity of Pietermaritzburg for the specific purpose that the organisation needs. This is a lesser issue but can still restrict the organisation's use of cloud 
computing services. As a case in point, one interviewee talked about their database that 'links everything together'.

Another amalgamated variable emerged from the data, and the term organisational IT has been adopted. Organisational IT is an umbrella term for the current use of IT as well as the effort necessary to implement a different or new IT service. There are several factors that fall into this category:

- Current IT: this is a measure of what IT the organisation is using at the moment, i.e. they either outsource or maintain in-house IT. Also relevant here is whether there is a specialised IT staff component within the organisation.

- IT spending: this factor relates to the overall spending on IT. If the company's spending is too small then there is less incentive to use cloud services because the cost of training and having specialised IT staff is greater than the cost saving. This could be linked to organisational size but is not explicit from the data. One response was, '[w]e do have people who would love to specialise in IT but it is just not financially worth it at the moment'.

- Effort: this measure relates to the time and effort needed to transfer current IT to the cloud. This includes the training time, the time to fix any miscellaneous errors that arise in the crossover as well as the cognitive effort it would take to learn the new process. In line with this, a comment was made stating that, '[with] the time taken to fix all the small problems, we'd rather pay for it', emphasising the time benefits of outsourcing.

An interesting point that originally did not appear in the literature and which seems to be very specific to each industry refers to legal restrictions and compliance. Within the financial services industry, there are guidelines for how data should be backed up, stored and protected. One respondent indicated that the use of the cloud to store and back up data was not compliant with the financial services guidelines. According to their compliance regulations, they must be able to prove they 'act in good faith' during data storage and backup. Another indicated that as long as the service provider adhered to the standards necessary then it was satisfactory. This legal restriction seems to be linked to 


\section{Mick Gouweloos \& Brian McArthur}

the fact that technology is increasing at a greater rate than that of related legislation in South Africa.

Surprisingly, cost seemed to be less important to two of the respondents than the quality of service. This is linked to trust of the service provided. The respondents were willing to pay a premium for a service that they knew was reliable. One respondent stated, 'as long as it is right, then we are willing to pay for it', indicating that they value other factors such as accuracy and system integrity above cost savings. Only one of the respondents indicated that they would definitely use a service that resulted in savings for the organisation.

There were several other smaller issues mentioned in the interview process that will be mentioned here for completeness. They have, however, not been included in a final model for the readiness of cloud computing services in order to focus on the key issues:

- Application rollout was mentioned as being easier with a central server that handles processing (as in cloud computing);

- Ability to work collaboratively over the cloud; and

- Cloud computing services have a core competency in the service they are offering so they should be good at what they do.

\section{Discussion and Interpretation}

Having discussed the findings of the interview process, some changes to the original conceptual model are proposed.

The revised conceptual model differs from the original one, as will be explained in this section. Where aspects have been renamed and/or altered this will be justified. Where factors are new, they will also be explained and lastly, the aspects that have been left out will be justified. The changes are grouped by the constructs perception and business readiness and will be mapped from the old model onto the new model.

Trust and risk have replaced stability, market support, market behaviour and security as constituent variables of the construct perception. Market support and market behaviour did not emerge during the interviews as factors included in the readiness for cloud computing so they have been 
removed. Stability and risk have been replaced with the more general description represented by trust and risk. Awareness is still a moderating variable but is even more important than originally anticipated.

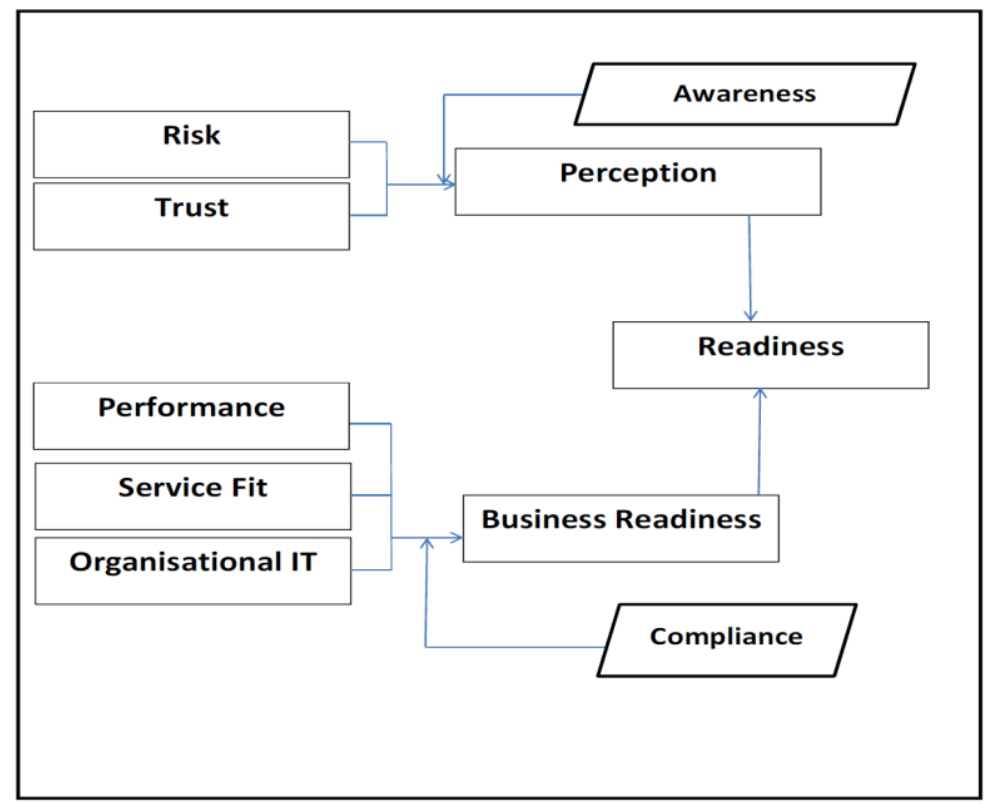

Figure 3: Revised conceptual framework for the analysis of an organisation's readiness for cloud computing services

Business readiness as a construct has some changes as well. Operations have been replaced by performance, which has a slightly wider scope as a variable. Infrastructure has also been swapped for organisational IT. Organisational IT encompasses a wider range of factors including infrastructure and IT staff. Compliance has been added as a moderating variable. This will account for legal and regulatory restrictions placed upon organisations; specifically for storage and protection of data in this context. Cost has been removed from the revised model because it has emerged as a factor that is not significant in this context. It is likely, however, that in many contexts this will be an important variable so it should not be discounted wholly. 


\section{Conclusion}

The cloud-computing paradigm shows signs of being a classic disruptive technology since it represents a radical departure from current practices (Staten et al. 2008); more specifically a technology that changes the way we use IT. Even so, there are both challenges and opportunities that cloud computing brings that must be dealt with if it is to succeed as a technology. Research has been done into whether or not cloud computing is ready for business consumption (Marston et al. 2010; Staten et al. 2008) and there is some suggestion that this service will support small businesses, yet there is relatively little research into this matter.

This study investigated the readiness of three small financial services organisations in the Pietermaritzburg region. In order to do this, the study aimed at answering three main questions:

- What are the readiness levels currently?

- Why are levels where they are?

- How would the adoption of cloud computing affect IT in these organisations?

These questions combine to present a picture of the readiness levels for cloud computing - the first two by viewing what the levels actually are and why they are there, and the last one by gauging how ready organisations are for cloud computing aside from awareness.

At the time of the research, the readiness levels in financial services organisations in Pietermaritzburg were not very high, according to the results obtained from interviewees. Of the three interview respondents, only one was superficially aware of the cloud-computing paradigm. This lack of awareness seems to underpin most of the perceptions of cloud computing. This links with the second question namely why the levels were where they were. The relatively low levels of adoption seem to be mostly a function of their awareness. With more knowledge and awareness of cloud computing, the organisations would be in a better position to decide whether or not cloud computing could benefit their organisations.

Lastly, the question was posed to respondents whether or not IT usage would change if cloud computing was a viable model. This allowed the researcher to view past the lack of awareness and see how ready the organisations were for cloud computing. This revealed some interesting results 
that were not obtainable in the first two questions. It revealed that the participating organisations were ready for the services that cloud computing can provide and the functionality that would accompany these services but are not necessarily ready for cloud computing itself.

There are implications about the sensitive and confidential nature of business information that made data generation difficult. This was less of an issue than originally thought due to the speculative and exploratory nature of the interviews. The researcher also emphasised confidentiality and the learning process throughout the interviews, which helped to mitigate confidentiality issues. Throughout the interview process, only one instance of data confidentiality occurred where specific details could not be discussed, so confidentiality was not generally a problem. However, confidentiality may have been an underlying issue that may have influenced the responses of the interviewees. The data that was generated from the interview process was rich in terms of an exploratory study into readiness for cloud computing; yet, there was a distinct lack of knowledge of cloud computing from respondents that made much of the data speculative.

The respondents who were interviewed were not IT specialists. This means that they were not in a position to have the knowledge necessary to take full advantage of the ideas presented by cloud computing. However, this general lack of expert IT knowledge represented the reality in terms of many small financial organisations.

This study may have alerted the participating companies to the advantages and disadvantages of cloud computing and could help to improve those individual businesses. Moreover, this study was exploratory and may be used to further the body of knowledge in this context. It could be further elaborated upon by other research and in a broader context. The research has also developed an initial framework for expansion and testing that could be used as a reference for further studies into cloud computing.

This initial conceptual framework represents aspects of readiness to adopt cloud computing in the small financial services sector. Lack of awareness of the risks and advantages of cloud computing has resulted in a situation where the risks appeared to outweigh the benefits to senior staff in the participating organisations. Perhaps financial services organisations need to explore the nature, characteristics and business opportunities of the cloud more thoroughly so that they can better judge whether it is an evanescent fad or an enduring source of competitive advantage. 


\section{References}

Armbrust, M., A. Fox, R. Griffith, A.D. Joseph, .R Katz, A. Konwinski, G. Lee, D. Patterson, A. Rabkin, I. Stoica \& M. Zaharia 2009. Above the Clouds: A Berkeley View of Cloud Computing. San Francisco: University of California, Berkeley. Rep. No. UCB/EECS-2009-28.

Armbrust, M., A. Fox, R. Griffith, A.D. Joseph, .R Katz, A. Konwinski, G. Lee, D. Patterson, A. Rabkin, I. Stoica \& M. Zaharia 2010. A View of Cloud Computing. Communications of the ACM 53,4: 50 - 58.

https://doi.org/10.1145/1721654.1721672

Aljabre, A. 2012. Cloud Computing for Increased Business Value. International Journal of Business and Social Science 3,1: 234 - 239.

Carr, N.G. 2003. IT doesn't matter. Educause Review 38: 24 - 38.

Glaser, B.G. 2001. The Grounded Theory Perspective: Conceptualization

Contrasted with Description. California: Sociology Press.

Goldner, M.R. 2010. Winds of Change: Libraries and Cloud Computing. Bibliothek Forschung und Praxis 34,3: 270 - 275.

https://doi.org/10.1515/bfup.2010.042

Gouweloos. M. 2011. Cloud Computing: A Readiness Study among Small Financial Services Organisations. Unpublished Honours research project. Hayes, B. 2008. Cloud Computing. Communications of the ACM, 51: 9 - 11. https://doi.org/10.1145/1364782.1364786

Iyer, B. \& J.C. Henderson 2010. Preparing for the Future: Understanding the Seven Capabilities of Cloud Computing. MIS Quarterly Executive 9,2: $117-131$.

Iyer, B. \& J.C. Henderson 2012. Business Value from Clouds: Learning from Users. MIS Quarterly Executive 11,1: 51 - 60.

Jackson, J. 2010. Many Managers See Cloud Computing as Risky Business. NetworkWorld. Available at:

http://www.networkworld.com/article/2206526/virtualization/manymanagers-see-cloud-computing-as-risky-business.html (Accessed on 26 October 2015.)

Joshi, R.K. \& D.J. Ram 1999. Anonymous Remote Computing: A Paradigm for Parallel Programming on Interconnected Workstations. IEEE Transactions on Software Engineering 25,1: 75 - 90.

https://doi.org/10.1109/32.748919

Kauffman, R.J., D. Ma \& M. Yu 2014. A Metrics Suite for Firm-Level Cloud 
Computing Adoption Readiness. In Altmann, J., K. Vanmechelen \& O.F. Rana (eds): Economics of Grids, Clouds, Systems, and Services: $11^{\text {th }}$ International Conference, GECON 2014, Cardiff, UK, September 16-18, 2014. Revised Selected Papers. Springer.

Kaufman, L.M. 2009. Data Security in the World of Cloud Computing. IEEE

Security \& Privacy 7,4: 61 - 64. https://doi.org/10.1109/MSP.2009.87

Linden, A. \& J. Fenn 2003. Understanding Gartner's Hype Cycles. Available

at: https://www.gartner.com/doc/396330/understanding-gartners-hype-

cycles (Accessed on 26 October 2015.)

Lynn, S. 2010. 1320 Top Cloud Services for Small Businesses. PC Magazine. Available at:

http://www.pcmag.com/article2/0,2817,2361500,00.asp (Accessed on 2 May 2012.)

Marston, S., Z. Li, S. Bandyopadhyay, J. Zhang \& A. Ghalsasi 2010. Cloud Computing - The Business Perspective. Decision Support Systems 51,1: 176 - 189. https://doi.org/10.1016/j.dss.2010.12.006

Misra, S.C. \& A. Mondal 2010. Identification of a Company's Suitability for the Adoption of Cloud Computing and Modelling its Corresponding Return on Investment. Mathematical and Computer Modelling 53,3: 504 - 521. https://doi.org/10.1016/j.mcm.2010.03.037

Morgan, L. \& K. Conboy 2013. Key Factors Impacting Cloud Computing Adoption. Computer 10: 97 - 99.

https://doi.org/10.1109/MC.2013.362

Motahari-Nezhad, H.R., B. Stephenson \& S. Singhal 2009. Outsourcing Business to Cloud Computing Services: Opportunities and Challenges. HP Laboratories. Rep. No. HPL-2009-23.

O'Leary, D.E. 2008. Gartner's Hype Cycle and Information System Research Issues. International Journal of Accounting Information Systems 9,4: 240 - 252. https://doi.org/10.1016/j.accinf.2008.09.001

Rappa, M.A. 2004. The Utility Business Model and the Future of Computing Services. IBM Systems Journal 43,1: 32 - 42.

https://doi.org/10.1147/sj.431.0032

Remenyi, D. 2011. Field Methods for Academic Research-Interviews, Focus Groups and Questionnaires. Academic Publishing International.

Sandelowski, M. 1995. Qualitative Analysis: What it is and How to Begin. Research in Nursing and Health 18,4: 371 - 375.

https://doi.org/10.1002/nur.4770180411 
Setyono, R. 2010. Exploring Cloud Computing for Tax Counseling at the Directorate General of Taxes of Indonesia to Achieve Citizen Centric Services. Available at: $\mathrm{http}: / / \mathrm{ssrn} . \mathrm{com} / \mathrm{abstract}=1684279$ (Accessed on 2 June 2016. https://doi.org/10.2139/ssrn.1684279

Staten, J., S. Yates, F.E. Gillett, W. Saleh \& R.A. Dines 2008. Is Cloud Computing Ready for the Enterprise? Forrester Research. Available at: https://www.forrester.com/report/Is+Cloud+Computing+Ready+For+Th e+Enterprise/-/E-RES44229 (Accessed on 2 June 2016.)

Vignos, J., P. Kim \& R.L. Metzer 2013. Demystifying the Fog: Cloud Computing from a Risk Management Perspective. Journal of Information Systems Applied Research, Special Issue: Cloud Computing 6,3: 4 - 17.

Yan, H. 2010. On the Clouds: A New Way of Computing. Information Technology \& Libraries 29,2: 87 - 92. https://doi.org/10.6017/ital.v29i2.3147

Mick Gouweloos School of Management, IT and Governance University of KwaZulu-Natal Durban $\underline{\text { mickgouweloos@yahoo.com }}$

Brian McArthur School of Management, IT and Governance University of KwaZulu-Natal Durban mcarthurb@ukzn.ac.za 